\title{
A Linguagem da Química OrgânICA: R ou S? Tem Mesmo a Certeza que Conhece o Sistema de Cahn - Ingold - Prelog?
}

Paulina Mata*

\begin{abstract}
Inicialmente proposto há cerca de 60 anos, o Sistema de Cahn-Ingold-Prelog (Sistema CIP) é o sistema de nomenclatura universalmente aceite para especificação de unidades estereogénicas em química. Este artigo descreve sumariamente 0 processo de evolução do Sistema CIP levado a cabo com a intervenção de pelo menos um dos seus proponentes (entre 1951 e 1982). Chama ainda a atenção para alguns aspetos da metodologia de aplicação do Sistema que são pouco referidos. Finalmente, ilustra algumas fragilidades da versão de 1982 do Sistema CIP e formas de as ultrapassar.
\end{abstract}

\section{INTRODUÇÃO}

Há cerca de 25 anos, para o meu trabalho de doutoramento, foi-me proposto que trabalhasse no programa LHASA (Logics and Heuristics Applied to Synthetic Analysis) [1], um sistema pericial informático para auxiliar o planeamento sintético. Este tem sido desenvolvido desde o início de 1960 , pelo grupo do Prof. E. J. Corey, da Universidade de Harvard, Prémio Nobel da Química em 1990 pela sua contribuição para a teoria e metodologia da síntese orgânica. $O$ trabalho seria coorientado pela Prof. Ana Lobo (Faculdade de Ciências e Tecnologia da Universidade Nova de Lisboa) e pelo Prof. Peter Johnson (School of Chemistry, University of Leeds), que colaborava com o Grupo de Harvard, e incidiria no desenvolvimento de certas componentes do módulo de perceção estereoquímica do LHASA, e particularmente aspetos relacionados com a implementação do Sistema de CahnIngold-Prelog ou, abreviadamente, Sistema CIP [2]. Havia situações que considerei complicadas e um grande desafio - o desconhecimento quase completo do LHASA (em desenvolvimento, na altura, desde há cerca de 30 anos e de grande complexidade) e os meus reduzidíssimos conhecimentos de programação. O que me parecia o problema de menor monta seria o domínio do Sistema CIP [3], que há muitos anos aplicava na espe-

\footnotetext{
REQUIMTE/CQFB, Departamento de Quimica, Faculdade de Ciências e Tecnologia (FCT), Universidade Nova de Lisboa (UNL), 2829-516 Caparica

E-mail: mpm@fct.unl.pt
}

cificação de unidades estereogénicas em química orgânica. Ironicamente, o Sistema CIP foi o maior desafio, mas também o mais apaixonante, uma ligação e um trabalho que nunca mais deixei até hoje. Vários foram os investigadores, e pessoas envolvidas no desenvolvimento de software, que me têm contactado ao longo destes anos para discutir e esclarecer dúvidas sobre este trabalho e, desde 2005, tenho o prazer de colaborar com a IUPAC (International Union of Pure and Applied Chemistry), nomeadamente como membro do Advisory Subcommittee of the Chemical Nomenclature and Structure Representation - Division (VIII). Foi também com grande prazer que vi o meu trabalho no Sistema CIP, e as alterações que propusemos para a sua componente designada por Regras de Sequência [4-6], ser considerado e analisado pela IUPAC. O Sistema CIP é uma ferramenta imprescindivel na nomenclatura de compostos químicos, e em particular em química orgânica, que é corrente e extensivamente usado em nomenclatura química há 60 anos. Consiste de um conjunto de convenções, com base nas quais a configuração absoluta das moléculas pode ser descrita de uma forma suficientemente compacta para permitir a sua inclusão no nome de cada composto. Não está publicada nenhuma descrição completa e compreensiva deste sistema, havendo uma proposta original que data de 1951 [7] e várias publicações subsequentes [3, 8-10] em que foram sugeridas extensões e alterações para tornar o Sistema mais completo e lhe permitir lidar com novas situações que foram surgindo com o desenvolvimento da química orgânica.

Geralmente, em particular em livros de química orgânica, o Sistema CIP é apresentado de forma excessivamente simplificada, que permite a sua aplicação a um número considerável de casos, mas apenas aos mais triviais, pode induzir em especificações erradas e não permite de todo lidar com situações mais complexas, sobretudo daquelas que ocorrem em moléculas quirais, mas com elevado grau de simetria no seu esqueleto.

Não é objetivo deste artigo apresentar uma análise exaustiva do Sistema CIP, nem a sua versão completa, mas apenas chamar a atenção para a fascinante história do seu desenvolvimento e a complexidade do processo envolvido na especificação de unidades estereogénicas. Pretende-se também prestar uma homenagem a R. S. Cahn, C. K. Ingold e V. Prelog (Figura 1), proponentes do Sistema CIP, que se reuniram para ampliar a linguagem da química orgânica, dotando-a de um sistema que ainda está em aperfeiçoamento.

\section{O Sistema CIP - ORIGEM E EVOLUÇÃO DE 1951 A 1982}

Na época em que o Sistema CIP foi proposto [7] ainda não havia forma de determinar a configuração absoluta de moléculas, embora alguns tipos de isomeria ótica em moléculas orgânicas fossem já conhecidos, nomeadamente envolvendo centros quirais (a grande maioria), mas também outros 
originados por sistemas bifenilo, alenos e espiranos. Na altura existiam vários sistemas para especificação da configuração relativa, baseados no sistema de nomenclatura $D / L$ (Figura 2 ), um sistema que atribuía descritores a centros quirais, correlacionando a configuração de cada centro com as atribuídas ao $D$ - e $L$ - gliceraldeído, mas que não era suficientemente geral e satisfatório.

As principais áreas da química orgânica que utilizavam este sistema eram as dos hidratos de carbono e aminoácidos, onde ainda são usados, já que funcionam relativamente bem internamente. Contudo, as metodologias de aplicação não eram suficientemente robustas e a sua extensão a outro tipo de moléculas era difícil e não permi- tia uma especificação das unidades estereogénicas coerente e sem ambiguidade. De facto, o motor de desenvolvimento do Sistema CIP foi, como resultado do rápido desenvolvimento da química orgânica, começarem a surgir moléculas cuja especificação pelo sistema $D / L$ era impossível.

A primeira publicação sobre o Sistema CIP [7] define as bases do sistema e remete-nos para 1951. Subsequentemente, de forma a torná-lo mais geral e coerente, foram introduzidas modificações e extensões por todos, ou apenas por alguns dos seus autores.

Este processo demonstra a natureza visionária de Cahn, Ingold e Prelog que, num estado de desenvolvimento inicial da química orgânica, tiveram a

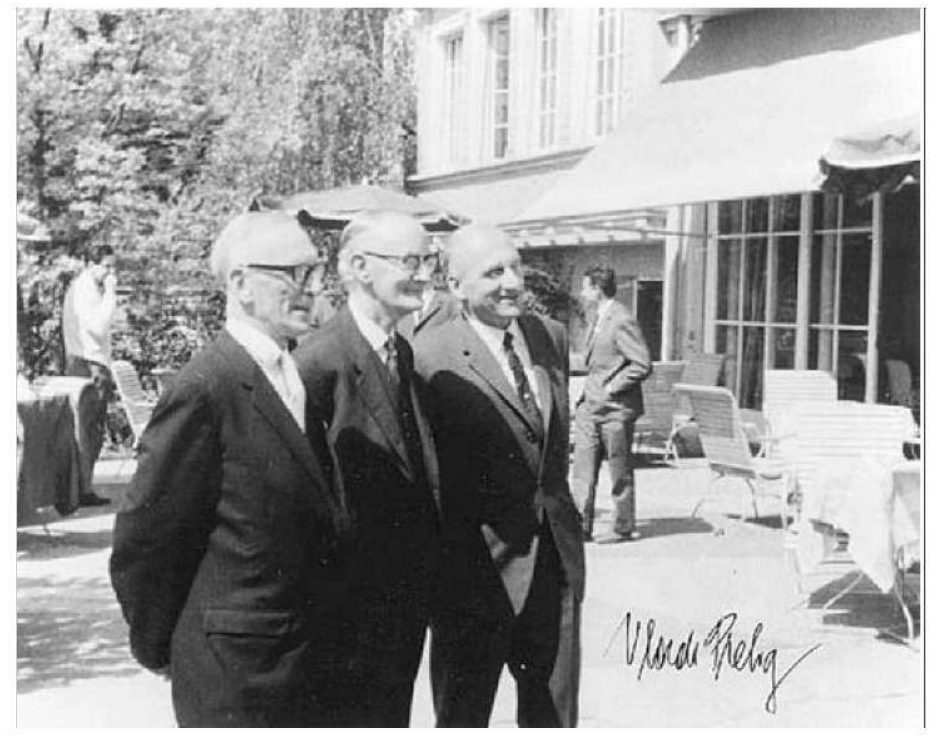

Figura 1 - Da esquerda para a direita [11]: R. S. Cahn (1899-1981) Editor do Journal of the Chemical Society; C. Ingold (1893-1970) University College, London; V. Prelog (1906-1998) Federal Institute of Technology (ETH), Zurich, Prémio Nobel da Química, 1975. Conferência de Burgenstock 1966<smiles>O=C[C@H]1C[C@@H](O)[C@@H](CO)C1</smiles>

$D$-gliceraldeído<smiles>O=C[C@H]1C=C[C@@H]2C=C[C@@H]1C2</smiles>

$L$-gliceraldeído<smiles>O=CC(O)C(O)C(O)[C@H](O)[C@H](O)CO</smiles>

$D$-glucose

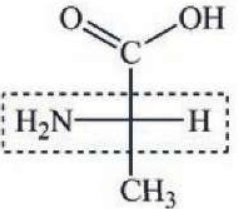

$L$-alanina
Figura 2 - Exemplos da aplicação do Sistema $D / L$ capacidade de antecipar a sua evolução futura e, particularmente, a possibilidade de determinação da configuração absoluta [12] e a necessidade da sua explicitação no nome dos compostos. Propuseram um sistema de nomenclatura que se revelou suficientemente robusto para absorver as adições necessárias, mantendo sempre consistência e obedecendo aos princípios lógicos da proposta original. Nas suas palavras [7], pretenderam "expressar a Regra de Correlação de uma forma generalizada, chamando-Ihe Regra de Sequência, de modo a que pudesse ser usada sem necessidade de ser modificada quando o conceito de substância de referência fosse abandonado". Pretenderam também que houvesse uma separação entre estas regras de nomenclatura e teorias químicas que pudessem evoluir ou ser modificadas no processo de desenvolvimento da ciência, de forma a que as regras tivessem uma base não efémera. Tais decisões revelaram-se fundamentais para que 0 núcleo base do Sistema CIP se mantivesse inalterado nos seus 60 anos de aplicação.

O Sistema CIP consiste basicamente de um conjunto de convenções - Regras de Sequência - que permitem hierarquizar os ligandos de uma dada unidade estereogénica, como por exemplo um centro quiral, com base nas suas características. Seguidamente, a Regra da Quiralidade (Figura 3) permite atribuir à unidade estereogénica um descritor ( $R$ ou $S$, no caso de centros quirais) que descreve inequivocamente a distribuição no espaço dos seus ligandos.

Na Tabela 1 apresenta-se um resumo do processo da evolução do Sistema CIP, em que as extensões e alterações foram apresentadas em publica-

$$
a>b>c>d
$$

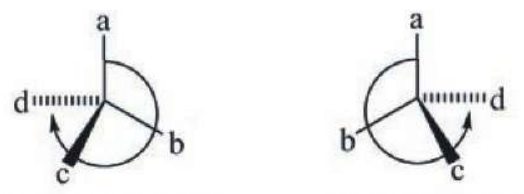

centro quiral $R$

$R$ - do latim Rectus (direito) $S$ - do latim Sinister (esquerdo)

Figura 3 - Regra da Quiralidade 
ções com a participação de pelo menos um dos seus autores. Na Tabela 2 apresenta-se um resumo da evolução das Regras de Sequência, parte inte- grante deste sistema e essencial para ordenar os ligandos das unidades estereogénicas, um processo que está na base do Sistema CIP. O desenvol- vimento e a aplicação das Regras de Sequência revelaram-se os aspetos mais complexos deste sistema.

Tabela 1 - Evolução das características do Sistema CIP (com exceção das Regras de Sequência) propostas pelos seus autores originais [3, 7-9]

\begin{tabular}{|c|c|c|c|c|}
\hline & 1951 & 1956 & 1966 & 1982 \\
\hline $\begin{array}{l}\text { Unidades } \\
\text { Estereogénicas }\end{array}$ & - Centros de assimetria. & $\begin{array}{l}\text { - Centros de assimetria; } \\
\text { - Eixos de assimetria; } \\
\text { - Planos de assimetria; } \\
\text { - Centros de pseudoassi- } \\
\text { metria. }\end{array}$ & $\begin{array}{l}\text { - Introdução dos termos } \\
\text { quiral e quiralidade; } \\
\text { - Metodologia para facto- } \\
\text { rização do modelo 3D em } \\
\text { sub-unidades quirais; } \\
\text { - Expansão do conceito } \\
\text { de centro quiral (Cabcd, } \\
\text { Caabb, Caaab e Caaa). }\end{array}$ & $\begin{array}{l}\text { - Introdução do conceito } \\
\text { de unidade estereogéni- } \\
\text { ca. }\end{array}$ \\
\hline Modelo & $\begin{array}{l}\text { - Estrutura 3D única com } \\
\text { ligações localizadas e de } \\
\text { multiplicidade inteira: } \\
\text { - "Convenções para a Se- } \\
\text { leção de uma Estrutura de } \\
\text { Valência". }\end{array}$ & & $\begin{array}{l}\text { - Estrutura 3D única, } \\
\text { combinação das várias } \\
\text { representações possíveis: } \\
\text { - "Convenções da Ligação } \\
\text { de Valência". }\end{array}$ & \\
\hline Metodologia & $\begin{array}{l}\text { - Convenção para conver- } \\
\text { são de ligações múltiplas } \\
\text { em ligações simples; } \\
\text { - Metodologia para for- } \\
\text { mação e ordenamento } \\
\text { dos conjuntos de átomos } \\
\text { a serem comparados nos } \\
\text { pares de ligandos. }\end{array}$ & & $\begin{array}{l}\text { - Alteração da conven- } \\
\text { ção para conversão de } \\
\text { ligações múltiplas em liga- } \\
\text { ções simples. } \\
\text { "Convenção para a } \\
\text { Complementação da Va- } \\
\text { lência". }\end{array}$ & $\begin{array}{l}\text { - Digrafos hierárquicos; } \\
\text { - Metodologia para aná- } \\
\text { lise de moléculas cíclicas; } \\
\text { - Conceito de descritor } \\
\text { auxiliar; } \\
\text { - Metodologia de compa- } \\
\text { ração de pares de descri- } \\
\text { tores. }\end{array}$ \\
\hline Descritores & $\begin{array}{l}\text { - De L; } \\
\text { - Atribuídos usando a } \\
\text { "Regra de Conversão"; } \\
\text { - Atribuídos a todos os } \\
\text { centros assimétricos da } \\
\text { molécula; } \\
\text { - Integrados no nome da } \\
\text { molécula. }\end{array}$ & $\begin{array}{l}\text { - } R \text { e } S ; \\
\text { - } r \text { es; } \\
\text { - Metodologia para atri- } \\
\text { buir descritores a eixos e } \\
\text { planos. }\end{array}$ & $\begin{array}{l}\text { - "Regra de Conversão" } \\
\text { denominada "Regra da } \\
\text { Quiralidade"; } \\
\text { - "Regra da Helicidade" } \\
\text { para especificação de con- } \\
\text { formações e estruturas } \\
\text { secundárias. }\end{array}$ & $\begin{array}{l}\text { - Eixos e planos especifi- } \\
\text { cados de preferência pela } \\
\text { "Regra da Helicidade" ( } M \text {, } \\
P) \text {. }\end{array}$ \\
\hline $\begin{array}{l}\text { Domínio de } \\
\text { Aplicação }\end{array}$ & $\begin{array}{l}\text { - Especificação de confi- } \\
\text { gurações relativas em quí- } \\
\text { mica orgânica. }\end{array}$ & $\begin{array}{l}\text { - Especificação de con- } \\
\text { figurações absolutas em } \\
\text { química orgânica. }\end{array}$ & $\begin{array}{l}\text { - Especificação de: } \\
\text {. configurações abso- } \\
\text { lutas em química orgâ- } \\
\text { nica; } \\
\text {. estruturas secundárias; } \\
\text {. conformações; } \\
\text {. configurações absolu- } \\
\text { tas em estruturas inor- } \\
\text { gânicas. }\end{array}$ & \\
\hline
\end{tabular}

Tabela 2 - Evolução das características das Regras de Sequência do Sistema CIP propostas pelos seus autores originais [3, 7-9]

\begin{tabular}{|c|c|c|c|c|}
\hline Regras de Sequência & 1951 & 1956 & 1966 & 1982 \\
\hline Regra - 0 & & $\begin{array}{l}\text { Grupo mais próximo tem } \\
\text { prioridade sobre grupo } \\
\text { mais afastado; }\end{array}$ & $\begin{array}{l}\text { Grupo mais próximo tem } \\
\text { prioridade sobre grupo } \\
\text { mais afastado; }\end{array}$ & $\begin{array}{l}\text { Grupo mais próximo tem } \\
\text { prioridade sobre grupo } \\
\text { mais afastado; }\end{array}$ \\
\hline Regra - 1 & $\begin{array}{l}\text { Maior número atómico } \\
\text { tem prioridade sobre me- } \\
\text { nor número atómico; }\end{array}$ & $\begin{array}{l}\text { Maior número atómico } \\
\text { tem prioridade sobre me- } \\
\text { nor número atómico; }\end{array}$ & $\begin{array}{l}\text { Maior número atómico } \\
\text { tem prioridade sobre me- } \\
\text { nor número atómico; }\end{array}$ & $\begin{array}{l}\text { Maior número atómico } \\
\text { tem prioridade sobre me- } \\
\text { nor número atómico; }\end{array}$ \\
\hline Regra - 2 & $\begin{array}{l}\text { Maior massa atómica tem } \\
\text { prioridade sobre menor } \\
\text { massa atómica. }\end{array}$ & $\begin{array}{l}\text { cis tem prioridade sobre } \\
\text { trans (para ligações du- } \\
\text { plas e substituintes em } \\
\text { anéis); } \\
\text { (Nota: Embora a regra re- } \\
\text { lativa à massa atómica se } \\
\text { mantivesse, era conside- } \\
\text { rada Regra - } 4 \text { nesta ver- } \\
\text { são do Sistema CIP) }\end{array}$ & $\begin{array}{l}\text { Maior massa atómica tem } \\
\text { prioridade sobre menor } \\
\text { massa atómica; }\end{array}$ & $\begin{array}{l}\text { Maior massa atómica tem } \\
\text { prioridade sobre menor } \\
\text { massa atómica; }\end{array}$ \\
\hline Regra - 3 & & $R$ tem prioridade sobre $S$ & $\begin{array}{l}\text { cis tem prioridade sobre } \\
\text { trans (para ligações du- } \\
\text { plas e substituintes em } \\
\text { anéis); }\end{array}$ & $\begin{array}{l}\text { cis tem prioridade sobre } \\
\text { trans; } \\
\text { (Nota: Para ligações du- } \\
\text { plas, os anéis passam a ser } \\
\text { considerados na Regra - } 4 \text { ) }\end{array}$ \\
\hline
\end{tabular}




\begin{tabular}{|c|c|c|c|c|}
\hline Regras de Sequência & 1951 & 1956 & 1966 & 1982 \\
\hline Regra - 4 & & $\begin{array}{l}\text { Maior massa atómica tem } \\
\text { prioridade sobre menor } \\
\text { massa atómica. }\end{array}$ & $\begin{array}{l}\text { - Pares like (RR, SS, MM, } \\
P P, R M, S P) \text { tem priorida- } \\
\text { de sobre pares unlike (RS, } \\
M P, R P, S M) \text {; } \\
\text { - } r \text { tem prioridade sobre s; }\end{array}$ & $\begin{array}{l}\text { Pares like tem prioridade } \\
\text { sobre pares unlike; }\end{array}$ \\
\hline Regra - 5 & & & $R>S ; M>P$. & $\begin{array}{l}-R \text { tem prioridade sobre } \\
S ; M \text { tem prioridade so- } \\
\text { bre } P \text {; } \\
-r \text { tem prioridade sobre } s .\end{array}$ \\
\hline Outros Aspetos & & & $\begin{array}{l}\text { Regras próprias para clas- } \\
\text { ses de simetria diferente } \\
\text { de C1. }\end{array}$ & $\begin{array}{l}\text { - Definição clara da hie- } \\
\text { rarquia de propriedades; } \\
\text { - Nova regra introduzida, } \\
\text { cuja hierarquia nas Regras } \\
\text { de Sequência não é clara- } \\
\text { mente definida: } \\
\text { Unidades estereogénicas } \\
\text { quirais precedem unida- } \\
\text { des pseudoassimétricas e } \\
\text { estas precedem unidades } \\
\text { não estereogénicas. }\end{array}$ \\
\hline
\end{tabular}

Metodologia geral de anÁlise de LIGANDOS No SISTEMA CIP

Ao longo do tempo, o conceito de ligando tornou-se cada vez mais complexo pelo que, para não haver ambiguidade, antes de se iniciar a análise, é fundamental transformar cada unidade estereogénica e os seus ligandos num digrafo herárquico [3], seguindo convenções bem definidas. De facto, o significado do termo ligando é claro no caso de ligandos monodentados e acíclicos, mas tal pode não acontecer no caso de ligandos cíclicos ou polidentados.

O digrafo hierárquico de cada unidade estereogénica é um sistema equivalente à molécula, acíclico e com toda a informação necessária para uma análise não ambígua dos ligandos.

Neste, os nodos (vértices, ou pontos de junção) representam átomos e as arestas representam ligações. As arestas são dirigidas da raiz do digrafo (nodo origem do digrafo, correspondente ao centro estereogénico) para o exterior. Os nodos estão hierarquizados, sendo esta hierarquia definida pela distância da raiz e pela aplicação das Regras de Sequência.

Será com base nestas unidades abstratas, em que cada átomo pode surgir na forma de diferentes nodos, em diferentes localizações e inclusivamente com diferentes características e posições hierárquicas dentro da estrutura, que a comparação deve ser feita.
No texto junto à Figura 4 descreve-se o processo de construção de um digrafo para um centro quiral numa molécula contendo anéis e ligações múltiplas. Na Figura 5 apresentam-se dois exemplos da construção dos digrafos hierárquicos de centros quirais integrados nas moléculas $A$ e $B$, com sistemas de anéis mais complexos.
Note-se, contudo, que os digrafos hierárquicos de diferentes unidades estereogénicas da mesma molécula têm características diversas, sendo importante construir um digrafo hierárquico para cada uma delas, como ilustrado na Figura 6 para três dos cinco centros quirais $(3,8$ e 10) da molécula apresentada.

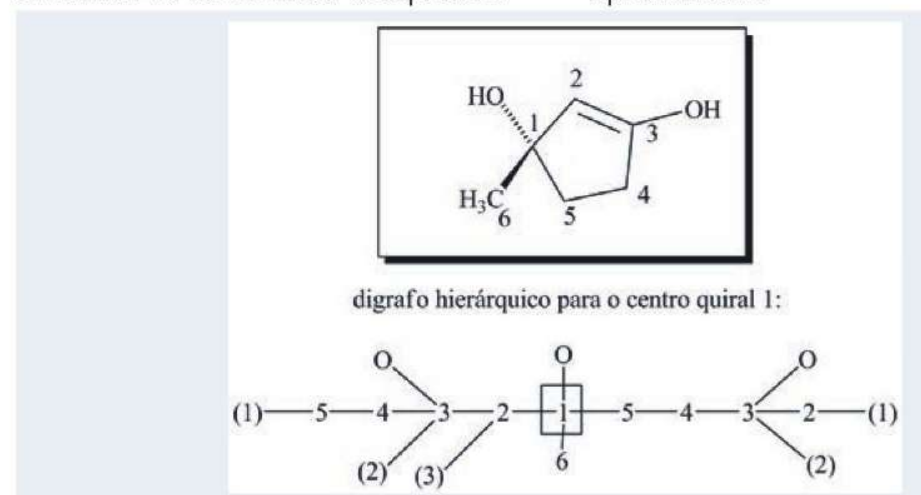

Na molécula acima todos os átomos de carbono foram numerados, de forma aleatória e apenas para identificação dos nodos a eles correspondentes no digrafo hierárquico.

O nodo que representa o carbono 1 , quiral, é o centro do digrafo (raiz do digrafo). Os seus ligandos deverão ser acíclicos, apenas com ligações simples, e deverão refletir inequivocamente a conectividade existente entre os átomos na molécula. Num digrafo simplificado, como o representado, os hidrogénio (exceto os ligados diretamente à raiz do digrafo) não são explícitos.

A representação dos ligandos correspondentes ao grupo álcool e ao grupo metilo é simples. Contudo, dado que o centro quiral está integrado num anel, é necessário, através da aplicação de um conjunto de convenções, transformar o ciclo em dois ligandos acíclicos.

Como exemplo, considere-se o ligando que começa no carbono 2. Os átomos do anel devem ser sucessivamente representados no digrafo, através de nodos identificados pelo seu número. Finalmente, o carbono 5 liga-se de novo ao centro quiral (carbono 1), este deve assim ser representado por um átomo duplicado - identificado pelo número 1 , com o número atómico do carbono, mas ao qual estão ligados três átomos fantasma, ou seja, com número atómico zero. Tal indica-se colocando o número correspondente ao átomo duplicado entre parêntesis.

O carbono 2 está ligado por uma ligação dupla ao carbono 3. Assim, no digrafo, ligados ao nodo que the corresponde aparecem dois nodos identificados com o número 3 , um deles duplicado.

Finalmente, ao carbono 3 , está ligado um átomo de oxigénio, o carbono 4 e ainda duas vezes o carbono 2, visto que está a ele ligado por uma ligação dupla. No digrafo, um destes surge como um átomo duplicado.

Para a construção do outro ligando, procede-se da mesma forma, mas explorando o anel no sentido inverso.

Figura 4 - Processo de construção de um digrafo para um centro quiral numa molécula contendo anéis e ligações múltiplas 
(a)

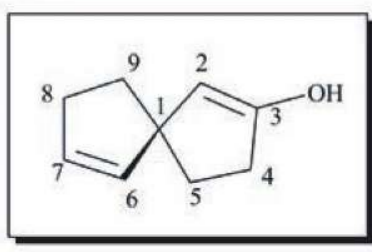

(b)

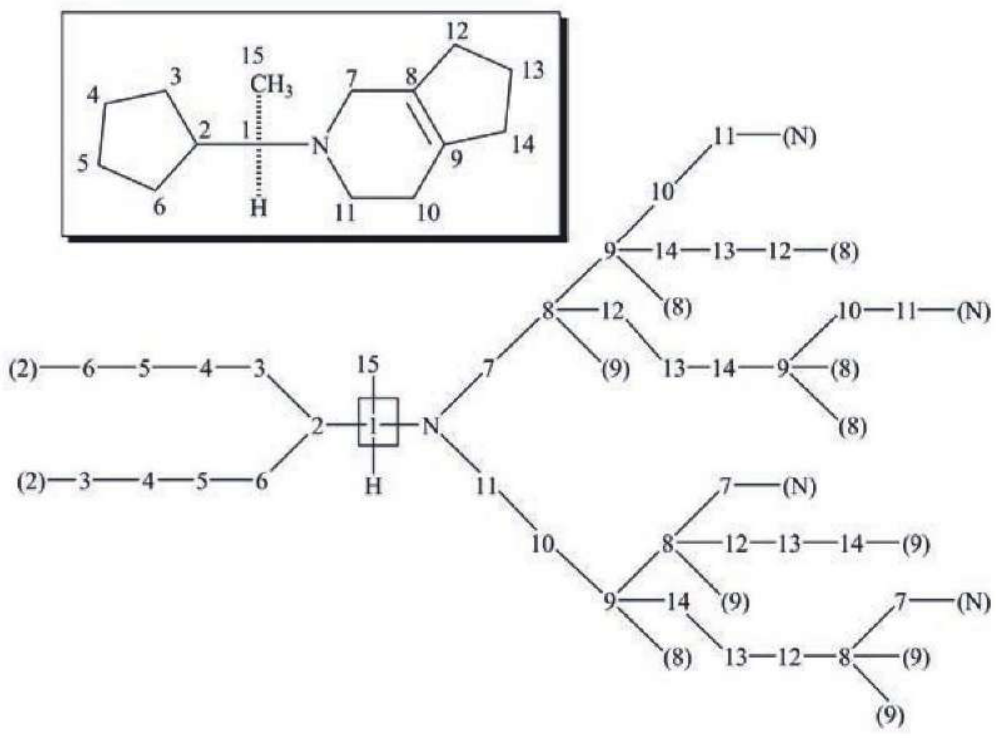

Figura 5 - Construção de digrafos hierárquicos para centros quirais em moléculas com sistemas de anéis com alguma complexidade

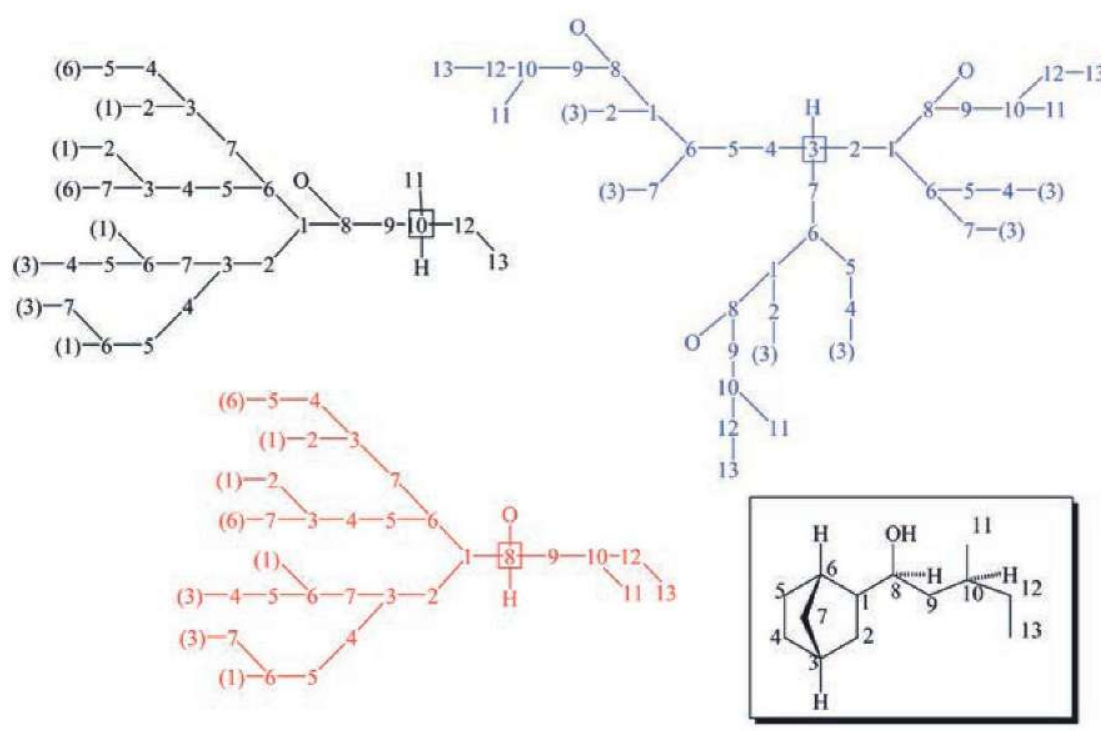

Figura 6 - Construção de digrafos hierárquicos para três unidades estereogénicas diferentes de uma mesma molécula
Uma vez o digrafo construído, os ligandos devem ser comparados pela aplicação das Regras de Sequência [3]. Nesta fase, um fator de importância decisiva para que toda a lógica do sistema seja mantida, é o respeito rigoroso da hierarquia do tipo de propriedades a comparar no processo de análise, ilustrada na Tabela 3. É também fundamental seguir escrupulosamente a ordem pela qual as propriedades devem ser analisadas dentro de cada categoria, fazendo a comparação de cada par de ligandos através da aplicação exaustiva e sucessiva de cada uma das Regras de Sequência.

Tabela 3 - Hierarquia das propriedades relevantes para ordenar ligandos [3]

\begin{tabular}{|c|c|c|}
\hline \multirow{3}{*}{ Hierarquia } & $\begin{array}{l}\text { CONSTITUCIONAIS } \\
\text { (materiais e } \\
\text { topológicas) }\end{array}$ & \multirow{2}{*}{$\begin{array}{c}\text { NÃO } \\
\text { VARIAM } \\
\text { COM A } \\
\text { REFLEXÃO }\end{array}$} \\
\hline & $\begin{array}{c}\text { GEOMÉTRICAS } \\
\text { (diastereomórficas) }\end{array}$ & \\
\hline & $\begin{array}{c}\text { TOPOGRÁFICAS } \\
\text { (enantiomórficas) }\end{array}$ & $\begin{array}{l}\text { VARIAM } \\
\text { COM A } \\
\text { REFLEXÃO }\end{array}$ \\
\hline
\end{tabular}

Durante o processo de comparação de pares de ligandos, o digrafo hierárquico não é uma estrutura estática, e sim dinâmica, em que a hierarquia dos diferentes nodos tem que ser continuamente avaliada, definida e refinada, mas nunca invertida. Este processo é fundamental para estabelecer a ordem pela qual os diferentes nodos devem ser comparados até encontrar a primeira diferença entre os ligandos e assim os hierarquizar de forma não ambígua.

Apresenta-se um exemplo na Figura 7, em que se representa uma parte do digrafo hierárquico correspondente a um dado ligando. Seguindo a convenção habitual de que no digrafo hierárquico, em cada momento da análise, os nodos superiores têm uma hierarquia igual ou superior à dos nodos inferiores em cada grupo, os três digrafos à esquerda na figura são inter-convertíveis e representam a hierarquia dos nodos depois de aplicada a Regra -1 .

Contudo, se tivermos em conta um versão simplificada do digrafo em que apenas surgem centros quirais e pseudoassimétricos, e os nodos são substituídos pelos seus descritores 
(apresentados do lado direito da figura), apenas dois dos digrafos (os dois inferiores) representam a hierarquia depois da aplicação da Regra - 4 b) (pares like precedem pares unlike) e apenas um deles (o que está na parte inferior da figura) é válido depois de aplicada a Regra - 4 c) ( $r$ precede $s$ ).

Um boa aplicação do Sistema CIP depende decisivamente da correta conversão de cada unidade estereogénica e seus ligandos no digrafo hierárquico e da comparação exaustiva e sucessiva das propriedades dos ligandos assim representados, ou seja, da aplicação das Regras de Sequência, para os hierarquizar. Este é um processo complexo, pouco familiar à generalidade dos químicos e, tanto quanto é do nosso conhecimento, não está descrito em nenhum livro de química orgânica. Constatámos, inclusivamente, que a sua implementação nos diversos programas de computador nem sempre é feita de modo correto.

Fragillidades do Sistema CIP e proPosta de alteração das Regras de SEQUÊNCIA

Apesar do processo de otimização do Sistema levado a cabo com a intervenção de pelo menos um dos seus autores originais, que culminou com a apresentação da versão de 1982 do Sistema CIP [3] (que nos parágrafos
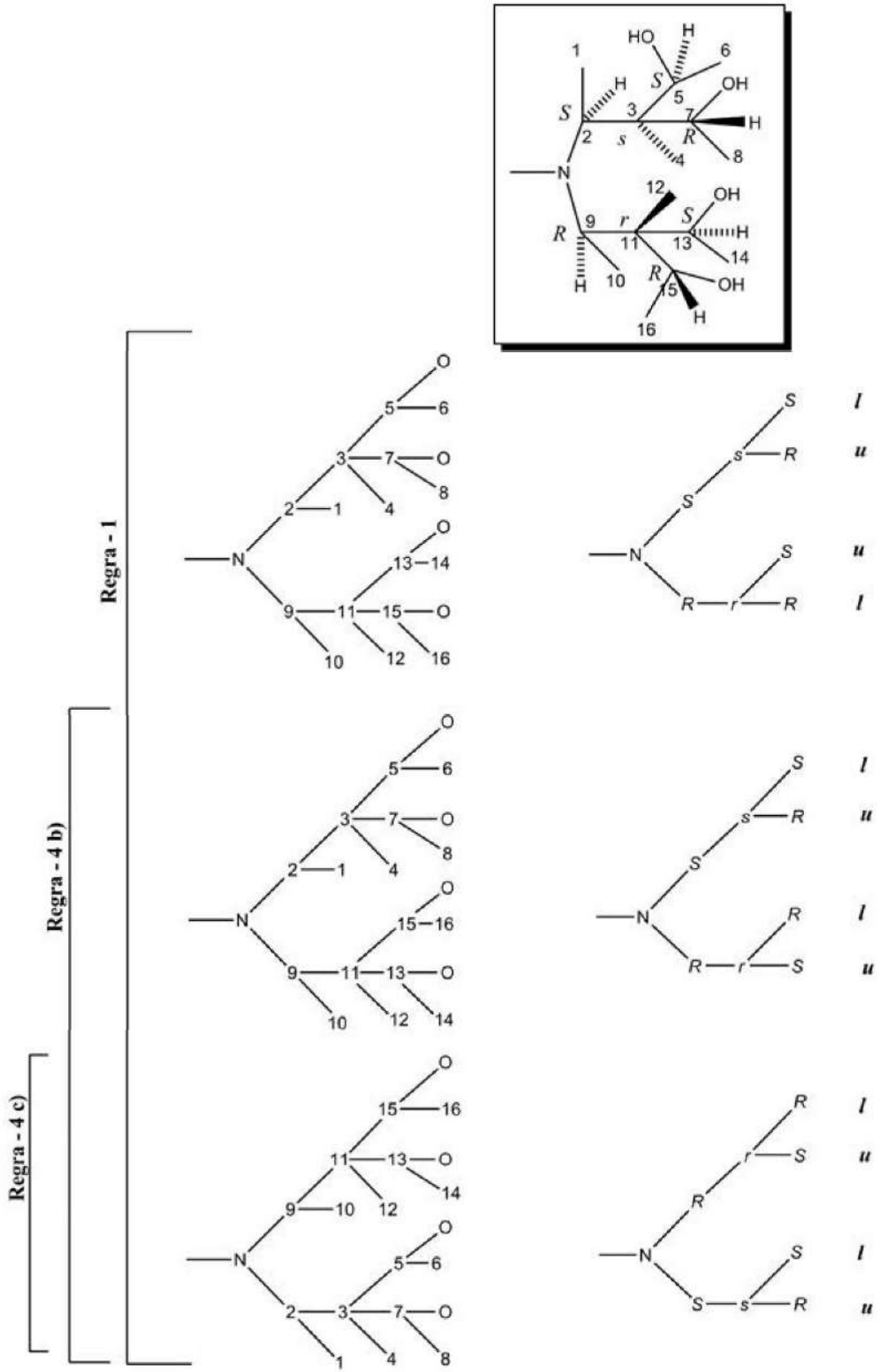

Figura 7 - Hierarquização dos nodos do digrafo hierárquico pela aplicação sucessiva das várias Regras de Sequência seguintes designaremos por versão original), o processo não ficou concluído. Ao longo dos anos têm sido identificados vários casos em que as Regras de Sequência são ambíguas, incoerentes ou incompletas [4-6, 1315], nalguns casos revelados em processos de implementação destas em sistemas informáticos para deteção e especificação da quiralidade [16]. Nos parágrafos seguintes apresentaremos alguns exemplos representativos.

A primeira regra a aplicar na comparação de ligandos de centros quirais do tipo Cabcd diz: Regra - 1 Maior número atómico tem prioridade sobre menor número atómico.

Esta regra, que permite hierarquizar a generalidade de ligandos de centros quirais, manteve-se inalterada desde o início, mas não permite contudo hierarquizar os ligandos do centro quiral 1 da molécula na Figura 8 [14] e do centro quiral 3 da molécula na Figura 9. Nomeadamente, distinguir os ligandos que nos digrafos hierárquicos de ambos estão na horizontal, apesar de nas moléculas serem obviamente diferentes. Para isso foi necessário introduzir uma nova sub-regra, não prevista na versão original do Sistema CIP: Regra - 1- c) Nodos de átomos duplicados cujo antecessor correspondente seja a raiz ou esteja mais perto dela precedem aqueles em que o antecessor correspondente está mais longe da raiz (nodo correspondente centro quiral) [14].

Tal permite em ambas as moléculas dar prioridade aos ligandos representados à direita.

A Regra - 3 da versão original também não permite distinguir os ligandos do centro quiral 1 da molécula da Figura 10 pela primeira diferença encontrada, o que justificou uma proposta de alteração para esta regra [4].

Por definição, os descritores atribuídos a um centro quiral variam com a reflexão, ou seja, um $R$ passa a $S$, e vice-versa, na imagem no espelho (enantiómero) de uma dada molécula. Este facto permite, inclusivamente, identificar enantiómeros pelo seu nome. Tratando todas as ligações duplas na Regra - 3, como preconizado por Cahn, Ingold e Prelog, isso não 


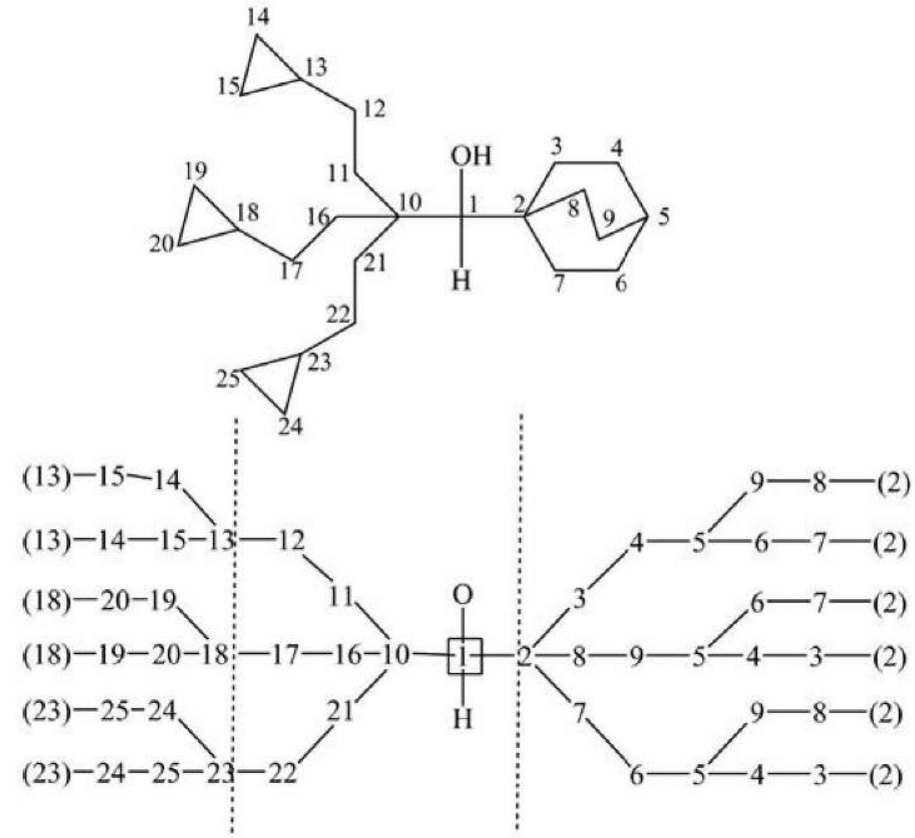

Figura 8 - Molécula cuja distinção dos ligandos do centro estereogénico 1 contendo os átomos 2 e 10 não pode ser levada a cabo pela Regra - 1 original, apesar destes serem constitucionalmente diferentes. Linhas a ponteado indicam diferenças que aplicando a Regra $-1 \mathrm{c}$ ) permitem diferenciar os ligandos

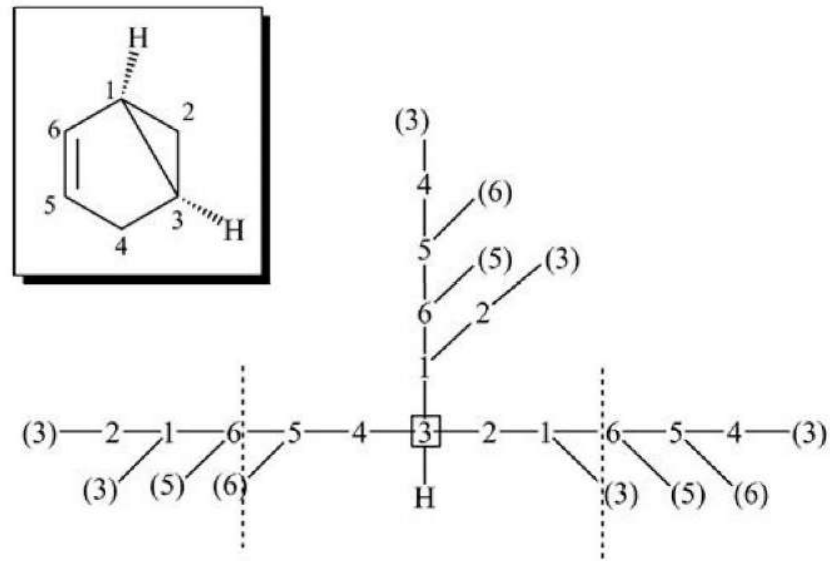

Figura 9 - Molécula cuja distinção dos ligandos do centro estereogénico 3, iniciados nos átomos 2 e 4 não pode ser levada a cabo pela Regra - 1 original, apesar destes serem constitucionalmente diferentes. Linhas a ponteado indicam diferenças que aplicando a Regra $-1 \mathrm{c}$ ) permitem diferenciar os ligandos

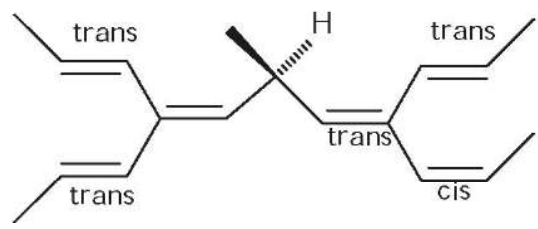

Figura 10 - Ligandos cuja hierarquização, usando o Sistema CIP original, não pode se feita pela primeira diferença encontrada na especificação das ligações duplas

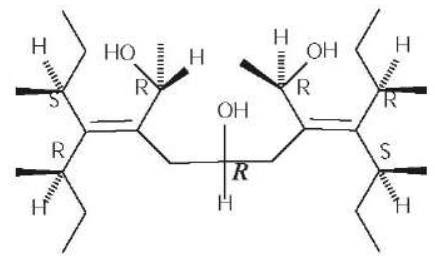

A

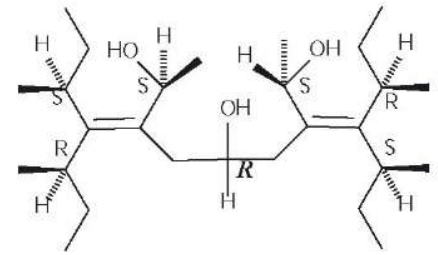

B
Figura 11 - Centro quiral cujo descritor atribuido pela versão original do Sistema CIP é o mesmo na molécula $A$ e no seu enantiómero $B$ acontecia sempre [13], como exemplificado na Figura 11. Tal justificou uma proposta para que as ligações duplas cuja especificação varia com a reflexão, como é o caso nesta molécula, não sejam consideradas na Regra - 3 , mas sim na Regra - 4, e o desenvolvimento de uma metodologia para a sua análise $[4,6]$.

Outros casos em que as regras propostas envolvem ambiguidade ou inconsistência incluem a hierarquização menos lógica de algumas regras, a metodologia para análise e comparação de ligações duplas e a metodologia para formação e comparação de pares de ligandos segundo a Regra - 4 [4-6].

Propusemos assim uma nova versão para as Regras de Sequência (ver Quadro 1) a utilizar na comparação de ligandos para especificação de unidades estereogénicas com base no Sistema CIP [4-6], cuja adoção está em análise pela IUPAC.

\section{Conclusão}

O Sistema CIP é uma ferramenta profusamente utilizada e indispensável à nomenclatura química. Após a proposta original em 1951, e até 1982, foram feitas várias revisões pelos seus autores para melhorar a sua lógica, consistência, âmbito e aplicabilidade. Apesar da sua robustez, ao longo dos anos têm sido encontradas algumas inconsistências neste Sistema que comprometem a sua implementação correta em sistemas informáticos. Tendo tido um envolvimento direto na apresentação de propostas de alteração, exemplificam-se algumas situações e apresenta-se uma versão alterada das Regras de Sequência, parte integrante do Sistema CIP, que permite ultrapassar os problemas encontrados.

A aplicação correta do Sistema CIP envolve uma metodologia complexa e rigorosa, pouco conhecida da maioria dos químicos, já que geralmente não é referida em livros de texto, que o apresentam de forma excessivamente simplificada. Neste artigo pretendeu-se alertar para a importância da aplicação completa da metodologia, de forma a especificar unidades estereogénicas de forma correta e não ambígua. 
Quadro 1 - Sistema CIP: Regras de Sequência [4-6]

Regra - 1:

a) Maior número atómico precede menor número atómico;

b) Nodos de átomos não duplicados precedem nodos de átomos duplicados;

c) Nodos de átomos duplicados cujo antecessor correspondente seja a raiz ou esteja mais perto dela precedem aqueles em que o antecessor correspondente está mais longe da raiz.

Regra - 2:

Maior massa atómica precede menor massa atómica.

Regra - 3:

Na comparação de ligações duplas geometricamente diastereomórficas e átomos tetraligantes planos, unidades estereogénicas seqcis precedem unidades estereogénicas seqtrans e estas precedem unidades não estereogénicas.

Regra - 4:

a) Unidades estereogénicas quirais precedem unidades estereogénicas pseudoassimétricas e estas precedem unidades não estereogénicas. Unidades estereogénicas bidimensionais geometricamente enantiomórficas precedem unidades não estereogénicas;

b) Escolhe-se para descritor de referência em cada ligando: i) o descritor associado ao nodo correspondente a uma unidade quiral de maior prioridade; ii) o descritor que ocorre em maior número no conjunto de nodos prioritários equivalentes; iii) sequencialmente ambos os descritores se estes ocorrem em igual número no conjunto de nodos prioritários equivalentes.

b1) Se o número de descritores de referência não é igual em ambos os ligandos, o ligando com um descritor de referência tem prioridade sobre o que tem dois descritores de referência;

b2) Se ambos os ligandos têm o mesmo número de descritores de referência, o descritor de referência é emparelhado com cada um dos descritores associados a nodos no digrafo correspondentes a unidades quirais por ordem decrescente de prioridade. Pares equivalentes em ambos os ligandos são comparados. Pares like (RR, SS, MM, PP, RM, SP, SeqCisseqCis, seqTransseqTrans, RseqCis, Sseqtrans, MseqCis, PseqTrans...) precedem pares unlike (RS, MP, RP, SM, SeqCisseqTrans, Rseqtrans, SseqCis, PseqCis, MseqTrans...).

c) $r$ precede $s$ e $m$ precede $p$.

Regra - 5:

$R$ precede $S ; M$ precede $P$ e seqCis precede seqTrans.

Alguns conceitos importantes:

Isómeros - compostos com fórmula molecular idêntica, mas diferindo na natureza ou sequência das ligações entre os seus átomos (isómeros estruturais), ou na distribuição destes no espaço (estereoisómeros).

Enantiómeros - moléculas que são a imagem uma da outra num espelho, não sendo contudo sobreponíveis (caso particular de estereoisómeros).

Isomeria ótica - caso particular de estereoisomeria que ocorre em moléculas quirais (não sobreponiveis com a sua imagem num espelho).

Unidade estereogénica - grupo de átomos, componente de uma molécula, que pode ser considerado um foco de estereoisomerismo (centro, eixo ou plano de quiralidade ou pseudoassimetria e ligações duplas que exibem isomerismo cis-trans).

Centro quiral - átomo (geralmente de carbono em química orgânica) com quatro substituintes diferentes (caso mais comum).

Centro de pseudoassimetria - átomo (geralmente de carbono em química orgânica) com quatro substituintes diferentes, mas em que os átomos de um par deles, e apenas de um par, estão relacionados um com o outro como objeto e a sua imagem num espelho.

Configuração absoluta - arranjo espacial de átomos ou grupos de átomos em torno de uma unidade estereogénica.

Configuração relativa - descrição do arranjo espacial de átomos ou grupos de átomos numa molécula, relativamente a uma substância de referência.

seqcis / seqtrans e seqCis / seqTrans - descritores associados a ligações duplas, usados na aplicação das Regras de Sequência e para cuja determinação se usam também as Regras de Sequência para hierarquizar os seus ligandos. Permitem ainda distinguir ligações duplas cuja especificação não varia com a reflexão (seqcis e seq trans) daquelas cuja especificação varia com a reflexão (seqCis e seqTrans).

Digrafo hierárquico - estrutura acíclica que representa uma unidade estereogénica e seus ligandos, e reflete a constituição da molécula usada para identificar e especificar unidades estereogénicas no Sistema CIP.

Raiz do digrafo - nodo inicial do digrafo, correspondendo à unidade estereogénica. 


\section{Agradecimentos}

Agradeço à Professora Ana Lobo o apoio e sugestões.

\section{REFERÊNCIAS}

[1] LHASA:http://lhasa.harvard.edu (LHASA Group at Harvard University, acedido em 06-01-2012)

[2] P. Mata, A. M. Lobo, C. Marshall, A. P. Johnson, J. Chem. Inform. Comput. Sci., 34, (1994), 491.

[3] V. Prelog, G. Helmchen, Angew. Chem. Int. Ed. Engl., 21, (1982), 567.

[4] P. Mata, A. M. Lobo, C. Marshall, A. P.
Johnson, Tetrahedron: Asymmetry, 4 (1993), 657.

[5] P. Mata, R. Nachbar, Tetrahedron: Asymmetry, 6, (1995), 693.

[6] P. Mata, A. M. Lobo, Tetrahedron: Asymmetry, 16, (2005), 2215.

[7] R. S. Cahn, C. K. Ingold, J. Chem. Soc., (1951), 612.

[8] R. S. Cahn, C. K. Ingold, V. Prelog, Experientia, 12, (1956), 81.

[9] R. S. Cahn, C. K. Ingold, V. Prelog, Angew. Chem. Int. Ed. Engl., 5, (1966), 385.

[10] R. S. Cahn, J.Chem.Ed.,41,(1964), 116

[11] Yale.edu: https://webspace.

y a le edu/chem $125 / 125 /$
history99/6Stereochemistry/CIP Prelog/prelstory.html (Yale University, acedido em 06-01-2012).

[12] J. M. Bijovet, A. F. Peerdeman, A. J. Van Bommel, Nature 168, (1951), 271

[13] H. Hirschmann, K. R. Hanson, Tetrahedron, 30, (1974), 3649.

[14] R. H. Custer, Match, 21, (1986), 3.

[15] K. C. Nicolaou; C. N. C. Boddy; J. S. Siegel, Angew. Chem. Int. Ed., 4 , (2001), 701.

[16] J. Aires-de-Sousa, "Representation of Molecular Chirality", in Handbook of Chemoinformatics, ed. Johnann Gasteiger,Wiley-VCH,1062-1078,2003.

\section{Atualidade Cientifica}

\section{UM NOVO CATALISADOR PARA ELIMINAR EMISSÕES DE METANO}

Foi desenvolvido um novo catalisador oxidante que pode permitir formas práticas para eliminar o metano dos gases de escape de motores de veículos. Pode também levar ao desenvolvimento de novos métodos para obter combustões mais eficientes (ou a uma redução de emissões) em turbinas industriais alimentadas a gás natural, cuja constituição é maioritariamente metano.

O metano é um gás com efeito de estufa muito potente, sendo uma substância presente na atmosfera que absorbe e emite radiação de uma forma que leva ao aquecimento da superfície terrestre. Até agora não tem sido prático reduzir as emissões de metano nos gases de escape de automóveis e de camiões devido ao facto dos catalisadores de oxidação de metano convencionais começarem a funcionar eficientemente apenas acima de $400^{\circ} \mathrm{C}$, uma temperatura típica dos gases de combustão nos tubos de escape. Por outro lado, os catalisadores existentes apresentam problemas de estabilidade quando as temperaturas dos gases de combustão se tornam muito mais quentes, como acontece quando os veículos sobem inclinações acentuadas ou são conduzidos em velocidades muito elevadas.

Agora existe um novo catalisador que oxida completamente o metano a $400^{\circ} \mathrm{C}$, desenvolvido recentemente pelos investigadores Raymond J. Gorte, da Universidade da Pennsylvania, nos E.U.A., e Paolo Fornasiero, da Universidade de Trieste, em Itália, e respetivos colaboradores (Science, DOI: 10.1126/science.1222887). Não foi ainda totalmente testado em condições reais, que tipicamente provocam mau funcionamento ou falhas nos catalisadores convencionais, mas os resultados já obtidos podem permitir o desenvolvimento de catalisadores que passem tais testes.

O novo catalisador consiste em estruturas supramoleculares distribuídas num suporte de alumina. As estruturas supramoleculares apresentam uma forma do tipo núcleo-coroa: o núcleo, de óxido de paládio, encontra-se ligado por iões metálicos e ligandos de coordenação a uma coroa protetora de estruturas de óxido de cério. O suporte de alumina sofre um tratamento especial com um composto organosilado, para o tornar hidrofóbico, melhorando a sua compatibilidade com as estruturas núcleo-coroa, que são também hidrofóbicas. $O$ catalisador ativa a oxidação do metano mais eficientemente a baixas temperaturas que outros testados. Alguns dos catalisadores anteriores conseguem conversões completas do metano apenas a temperaturas superiores a $600^{\circ} \mathrm{C}$. $\mathrm{E}$ alguns degradam a temperaturas acima dos $600^{\circ} \mathrm{C}$, enquanto que o novo catalisador permanece intacto até temperaturas de $850^{\circ} \mathrm{C}$.

Os investigadores que desenvolveram o novo catalisador ainda não testaram a sua capacidade para oxidar metano em veículos com atmosferas nos gases de escape contendo espécies desactivadoras de catalisadores tipicamente presentes nessas atmosferas, como compostos de enxofre, componentes de aditivos de óleos e vapor de água. Edman Tsang, da Universidade de Oxford, um especialista em catálise e em energias limpas, afirma que "existe uma necessidade enorme de remoção de pequenas quantidades de metano dos gases de exaustão de turbinas a gás e de motores de combustão interna e de gases de combustão das indústrias petroquímica e outras indústrias relacionadas. A baixa atividade normalmente apresentada pelos catalisadores convencionais e a sua instabilidade a elevadas temperaturas tornaram este desafio difícil, enquanto o novo catalisador representa um primeiro passo no sentido de uma solução. A abordagem necessita de mais avaliações, mas fornece uma clara direção para investigação futura".

Friedrich Esch, da Universidade Técnica de Munique, especialista em superfícies catalíticas e agregados, concorda que os pontos fortes e fracos do catalisador necessitam de mais avaliações, mas diz que "é um sistema muito efetivo para a combustão do metano, e que é este tipo de controlo e de preparação sistemática de catalisadores que fornece os alicerces para o projeto racional de catalisadores feitos à medida". No futuro, Gorte, Fornasiero e colaboradores esperam aprender mais sobre o mecanismo de ação do catalisador, de modo a desenvolver versões modificadas com capacidades melhoradas para a oxidação do metano, e projetar catalisadores similares para outras reações. 


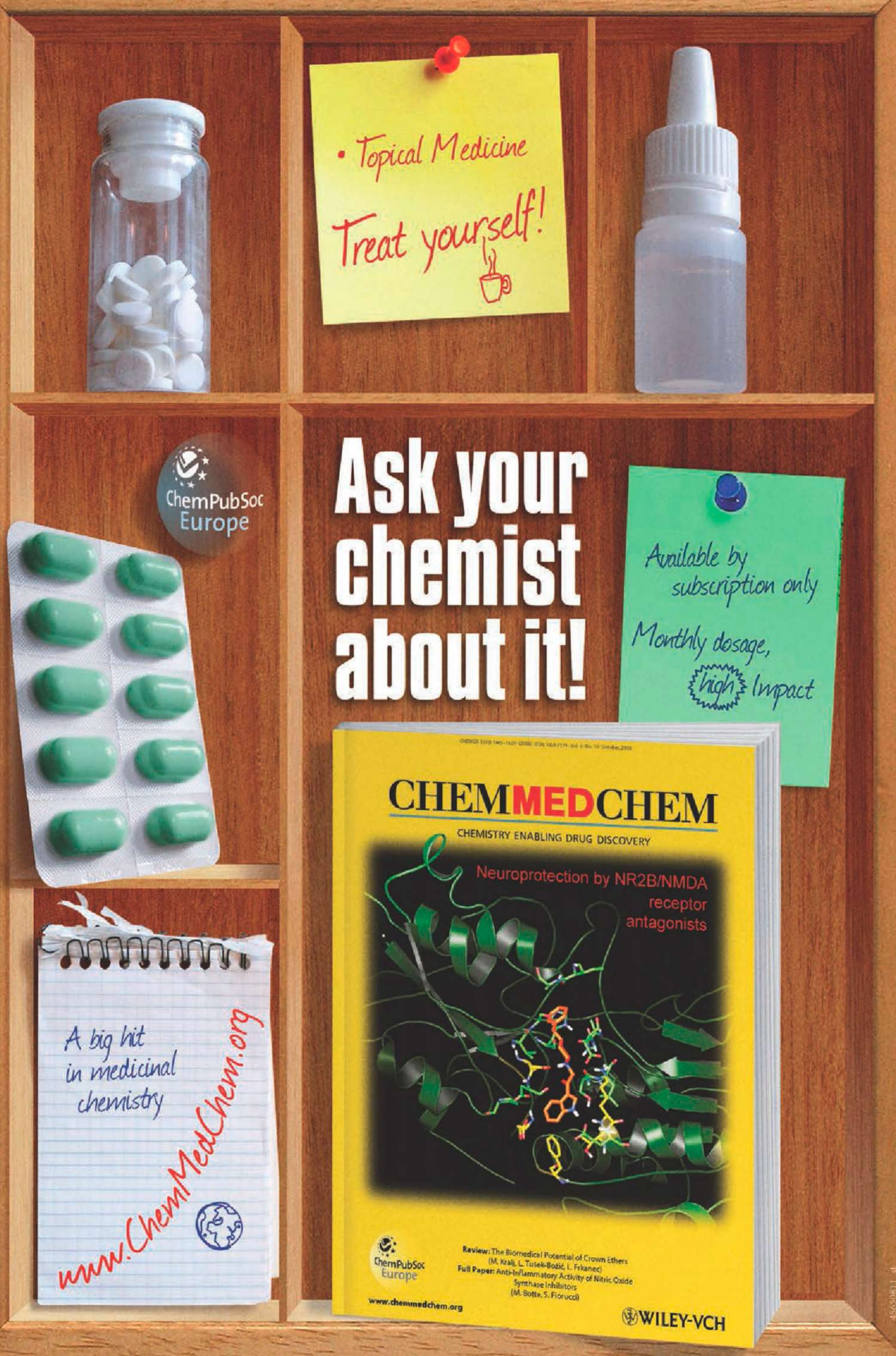

